\title{
TENTATIVA DE TRANSMISSÃO DA LEISHMANIA DONOVANI PELA PICADA DE LUTZOMYIA LONGIPALPIS, ENTRE CÃES
}

\author{
ftalo A. Sherlock $* *$ e Vilma A. Sherlock ***
}

\begin{abstract}
Os Autores apresentam dados sôbre tentativas de transmissão experimental da Leishmania donovani pela picada de Lutzomyia longipalpis entre cães. Dois câes jovens sadios foram picados respectivamente por dois e sete flebótomos ricamente infectados e não adquiriram leishmaniose.
\end{abstract}

Embora Lutzomyia longipalpis (Lutz \& $\therefore$ :iva, 1942) seja incriminada, epidemiolòミcamente, como a principal transmissora $\vdots$ ¿Leishmania donovani (Laveran \& Mens:... 1903), nos principais focos de Calazar $\vdots$ Novo Mundo, a prova experimental da :-ansmissão do protozoário pela picada de :-ptero, jamais foi conseguida(2-3).

Em 1958, em Fortaleza, Estado do Cea$\therefore$ ¿. fizemos algumas tentativas experimen: $:$ s para transmitir o protozoário pela pizada do flebótomo, sem entretanto obter... js resultados positivos. Por solicitação $\therefore$ interessados no assunto, publicamos ¿ora os dados dêsses experimentos.

\section{$\because A T E R I A L$ E MÉTODOS}

Para fonte de infecção dos flebótomos, ::am usados três cães adultos, naturalmente infectados por leishmânia nos fo:s do Estado do Ceará, que tinham a sin-.matologia típica da doença canina.

Dois cães jovens de 2 a 3 meses, um .... acho e uma fêmea, foram picados pelos $\therefore$ : jótomos infectados em laboratório. Um -..tro cão jovem foi inoculado, intraperi:nealmente, com macerado dos mesmos flebótomos infectados. Essses animais eram mantidos isolados dos demais suspeitos de leishmanioses e tomávamos também o cuidado para que não se infestassem com carrapatos. Recebiam uma dieta abundante em carne e cereais.

Utilizamos 990 exemplares fêmeas de L. longipalpis, criadas em laboratório, conforme técnica que já descrevemos(t).

Os flebótomos eram colocados para sugar o cão por meio de uma caixa de papelão com tampa de vidro, que era amarrada no ventre do animal. Os dipteros neste dispositivo podiam ficar em contacto direto com a pele do cão, da qual, prèviamente, eram raspados os pelos. Nas últimas horas da tarde, ouando os flebótomos pareciam mais ávidos para a sucção, eram postos para se alimentarem durante cêrca de 2 horas. No intervalo entre as sucçōes no animal infectante e no animal sadio, os flebótomos eram alimentados com passas escaldadas, cujo processo parecia enriquecer a infecção no díptero e facilitar a migração das leptomonas para a porção anterior do tubo digestivo(5).

Com o passar de alguns dias, os flebótomos suspeitos de estarem infectados - Trabalho do Núcleo de Pesquisas da Bahia do Instituto de Endemias Rurais - Fundação Instituto
Osvaldo Cruz, e Fundação Gonçalo Muníz

- Núcleo de Pesquisas do I.N.E.Ru., Salvador - Bahia

- Setor Ceará da SUCAM, Fortaleza - Ceará

Recebldo para publicação em 29/11/1971 

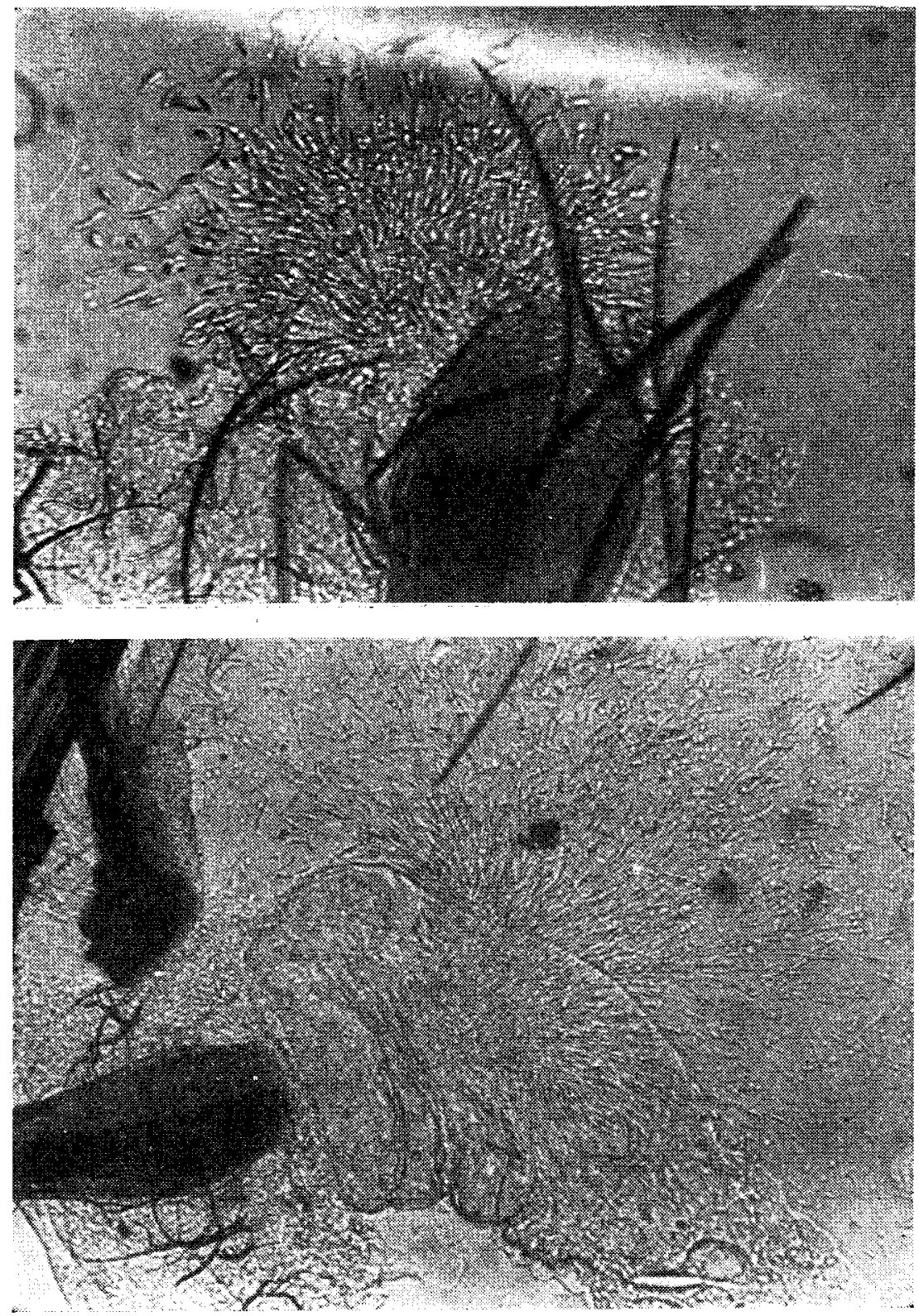

rjus I 2 - Bloqueio esofageano por Leishmania acnovani em Lutromyia longipaipis infectada experimentamente em cão com leishmaniose naturalmente parasitado em foco de Calazar. 
$\because 2 \mathrm{~m}$ postos para sugar os animais sadios. $\therefore$ ¿js engurgitados de sangue, os seus tu$:=$ digestivos eram dissecados para a pes:-:sa de flagelados.

\section{$\Xi \equiv$ SULTADOS}

Apesar das dificuldades que existem : ¿za obtenção de flebótomos criados $\mathrm{em}$ $\vdots$ ¿oratório, foram realizadas 50 tentativas ¿ infecção de flebótomos em 3 cães doen$\therefore$. com 990 exemplares de $L$. longipalpis $\Sigma$ colônia que mantínhamos. Dos 222 $\because \Sigma \equiv$ mplares examinados, 59 estavam positi-: para flagelados $(27 \%)$.
Vários dêstes também estavam infectados. Dessa forma, certamente, os animais foram, pelo menos, picados por muito mais flebótomos infectados de que os assinalados na Tabela I.

Os flebótomos infectados que sugaram os cães sadios o fizeram num período de 6 a 8 dias após terem sugado o cão doente. Isso porque havíamos observado anteriormente que, com êsse período de tempo, o flebótomo já necessitava de nova alimentação sanguínea e que as infecções eram mais ricas (5). o cão n.o 2, durante 7 dias foi, em média, picado por um flebótomo infectado, cada dia. Os dados

Tabela I

\section{-. LONGIPALPIS EXPERIMENTALMENTE INFECTADOS EM CÃES PARASITADOS NATURALMENTE POR L. DONOVANI QUE SUGARAM CÃES SADIOS}

\begin{tabular}{c|c|c|c}
\hline Cão & $\begin{array}{c}\text { No de flebótomos sus- } \\
\text { peitos postos a sugar }\end{array}$ & $\begin{array}{c}\text { No de flebótomos sus- } \\
\text { peitos engurgitados } \\
\text { de sangue }\end{array}$ & $\begin{array}{c}\text { No de flebótomos en- } \\
\text { gurgitados positivos }\end{array}$ \\
\hline 1 & 34 & 5 & 2 \\
2 & 63 & 26 & 7 \\
Total & 97 & 31 & 9 \\
\hline
\end{tabular}

Foram colocados para sugar os dois Eミs sadios, 97 exemplares de $L$. longipal$\therefore$. suspeitos de estarem infectados. Dos $\because$ exemplares que seguramente sugaram $\therefore$ animais e ficaram engurgitados, 9 es$=$. $\mathrm{m}$ ricamente positivos para leptomo$=$ inclusive com bloqueio de esôfago Eミs. 1 e 2). Teòricamente, poderia ter zinsmitido a leishmania por meio da pi: ¿a (Tabela I). O cão n. 1 foi picado $\because$ flebótomos infectados seguramente : : $: \vdots$ vêzes e o cão n. ${ }^{\circ} 2$, sete vêzes.

Somente foram computados como proZis transmissores os 9 flebótomos que, I.:- a alimentação no animal sadio, esta$T=$ positivos e com sangue nos tubos diミ:-:vos. Entretanto alguns dos 97 flebó$\because:=$ s suspeitos de infecção que, após co$\because a c i o s$ nos cães sadios para alimentarem$\because \equiv$ tinham os tubos digestivos isentos de $\Xi \div z$ ácias, foram vistos picar êsses animais. sôbre o tempo de infecção dos flebótomos foram os seguintes (Tabela II) :

T abela I I

\begin{tabular}{|c|c|c|}
\hline Cão & $\begin{array}{c}\text { N.o de flebóto- } \\
\text { mos infectados } \\
\text { que sugaram }\end{array}$ & $\begin{array}{l}\text { N.o de dias } \\
\text { de infecção } \\
\text { do flebótomo }\end{array}$ \\
\hline 1 & 2 & 6 \\
\hline 2 & 2 & 7 \\
\hline 2 & 5 & 8 \\
\hline
\end{tabular}

Os 9 flebótomos que estavam positivos e sugaram os cães sadios tinham ricas infecções. Os leptomonas localizavam-se próximos à válvula esofageana, formando

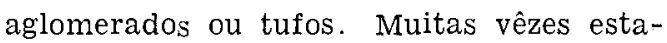
vam quase imóveis e aderidas às paredes do esôfago. Outras vêzes bastante móveis, com formas finas, longas, largas, curtas 
ou arredondadas, predominando as formas finas. De uma maneira geral, formavam bloqueios do esôfago, e também podiam ser vistas no estômago e até nas peças bucais. Jamais foram vistas no intestino posterior (Figs. 1 e 2).

O cão n. ${ }^{\circ} 1$ foi observado por cêrca de quatro meses após ser picado por flebótomos infectados, tendo sido feitas algumas pesquisas diretas de leishmanias na sua pele e sangue. Morreu nesse periodo, com uma infecção bacteriana secundária. Foram entäo examinados esfregaços das diversas vísceras as quais sempre forneceram resultados negativos.

O cão n. 2 foi observado durante 8 meses após as picadas dos flebótomos infectados. Periòdicamente, eram feitos esfregaços da ponta da oreiha e uma vez feita a punção de medula óssea para a pesquisa de leishmania. Mesmo após 1 ano e meio, o cão manteve seu aspecto sadio, tendo sido reexaminado nessa oportunidade, com resultados também negativos.

O cão n. ${ }^{\circ}$, inoculado intraperitonealmente com macerados de flebótomos infectados, também permaneceu negativo em todo $_{\mathrm{S}}$ os exames nele realizados.

\section{COMENTÁRIOS}

Teòricamente, bastaria a picada de um único exemplar de flebótomo infectado para que o animal adquirisse a doença. Entretanto, isso não ocorreu em nossos experimentos e nem nos que os outros pesquisadores têm descrito( $^{(2-3)}$.

Pondo de lado o fato de que, nos nossos experimentos, o número de animais sadios utilizados foi mínimo, podem ser aventadas algumas hipóteses para explicação do insucesso verificado. Em primeiro lugar, pensa-se que seja dificílima a transmissão da leishmânia na natureza e que seriam necessárias repetidas picadas de flebótomos e inoculações de leptomonas.

Outra hipótese seria a de que os cães novos oriundos de áreas calazarígenas, como é o caso dos que utilizamos, teriam uma imu- nidade congênita temporária à tal tipo de protozoose, como soe acontecer com algumas doenças infecciosas.

Ainda, como já tem sido salientado( $(\boldsymbol{z})$, existiria um "fator especial" em natureza, que tornaria o flebótomo mais capacitado a transmitir a leishmânia. Aliás, já salientamos noutra publicação(j) que “... se alimentamos fêmeas de flebótomos capturadas na natureza, em animais doentes, obtemos uma percentagem mais alta de infecção", quando comparamos com as taxas de infecção dos flebótomos criados em laboratório.

Referindo-nos à alimentação açucarada que tornava as infecções dos flebótomos em laboratćrio mais ricas, salientamos que os flebótomos em natureza, tanto os machos como as fêmeas, sugam talos vegetais. Ainda comparando a taxa de infecção experimental dos flebotorios coletados em naturea expressamos que: "Isso pondo de lado a possibilidade de infecção natural, nos insinua que a fêmea, provàvelmente se alimentara de tais substâncias"(j). Dessa forma, a alimentação açucarada no laboratório, seria o substituto dos sucos vegetais. Talvez por essa razão é que Coelho(1), que utilizou nas suas observações flebótomos coletados na natureza, não observou diferenças na riqueza de parasitas nos exemplares que infectou alimentados ou não com substâncias açucaradas.

Era patente nos nossos experimentos a ação dessas substâncias na riqueza e migração das leptomonas para a porção anterior do tubo digestivo do flebótomo. A real importância ou interferência dessas substâncias na transmissão da leishmânia ainda continua obscura .

Evidentemente, o número de experimentos que realizamos foi muito pequeno. Entretanto, número considerável de experimentos tem sido levado a efeito, mesmo com outras espécies de diptero e de leishmanias. E como Coelho(1) salienta, tem sido obtida a transmissão da leishmânia pela picada de flebótomos, no entanto "são mais numerosos os insucessos que os resultados positivos, o que parece indicar que ainda permanecem desconhecidos os fatôres que condicionam a transmissão das leishmânias pelos flebótomos". 
SUMMARY

In 1958, attempts were made to transmit Leishmania donovani (Leveran \& Mensnil) from dog to dog by the bite of Lutzomya longipalpis (Lutz \& Neiva) in the State of Ceará, Brazil.

Two young, healthy dogs (2-3 months old) were bitten by 31 laboratory reared sanflies fed previously on infected dogs; nine of the sandflies were later found to be infected with L. donovani, but none of the healthy dogs on which they fed became infected.

\section{REFERÊNCIAS BIBLIOGRÁFICAS}

1. COELHO, M. de V. - Desenvolvimento de espécies do gênero Leishmania em espécies brasileiras de flebótomos do gênero Lutえomyia França, 1924. Tese. Faculdade de Medicina da Universidade Federal de Minas Gerais 68 pp. Mimeografada, 1566 .

2. DEANE, L. M. - Leishmanioses visceral no Brasil. Estudos sôbre reservatórios e transmissores realizados no Estado do Ceará. Serv. Nac. Educ. Sanit. Rio de Janeiro, Brasil, 162 pp., 1956.

3. LAINSON, R. \& SHAW, J. J. - Epidemiological considerations of the leishmanias with particular reference to the New World. In "The Ecology and Physiology of Parasites." Ed. Fallis A. M., University of Toronto. Toronto Press, pp. 21-57, 1971.

4. SHERLOCK, I. A. \& SHERLOCK V. A. - Criação e Biologia, em laboratório, de Phlebotomus longipalpis, Lutz \& Neiva, 1912 (Diptera, Psychodidae). Rev. Brasil. Biol., 19: 229-250, 1959.

5. SHERLOCK, I. A. \& SHERLOCK V. A. - Sôbre a infecção experimental de Phlebotomus longipalpis pela Leishmania donovani. Rev. Brasil. Biol., 21: 409-418, 1961. 